\title{
Arabic Numerals Recognition Using Linear Correlation Algorithm in Two Dimension
}

\author{
Gafar Zen Alabdeen Salh \\ Department of IT \\ Faculty of Computers and IT \\ King Abdulaziz University \\ Khulais, Saudi Arabia
}

\author{
Abdelmajid Hassan Mansour \\ Department of IT \\ Faculty of Computers and IT \\ King Abdulaziz University \\ Khulais, Saudi Arabia
}

\author{
Abdelhafeez hamid mohammed \\ Department of CS \\ Faculty of CS and IT \\ Kassala University \\ Kassala, Sudan
}

\begin{abstract}
The process of handwriting recognition and text is an important field which have a large role in many applications, including the identification of manually written digits on checks and documents, also the recognition of the postal addresses using the technology of Optical Character Recognition (OCR), and etc. The aim of this paper is to using the linear correlation algorithms in two dimensions for the purpose of Arabic numerals (Indian) recognition (0-1-2-3-4-5-6-7-8-9). So as to overcome the problems of documents that stored in the form of image. And searching or editing it, In order to recognize the Arabic digits on them.
\end{abstract}

Keywords: Optical Character Recognition; Handwriting; Image Processing; Pattern Recognition; artificial Neural Networks

\section{INTRODUCTION}

The handwriting recognition refers to the identification of written characters. Handwriting recognition has been become a very important and useful research area in recent years for the ease of access of many applications [2].

Numeral recognition refers to the process of translating images of handwritten, typewritten, or printed digits into a format understood by the user for the purpose of editing, indexing, searching and reduction in storage size .Number recognition can be online or offline. In online number recognition, data are captured during the writing process with the help of special pen and an electronic interface. Offline documents are scanned images of prewritten text, generally on sheet or paper [2].

Handwritten character recognition is a field of image processing as well as pattern recognition. There are two approaches for the pattern recognition such as statistical and structural. In statistical approach, the characteristic measurements of the input data is generated on the statistical basis and is assigned to one of the $\mathrm{n}$ classes. The structural description of the object is based on the interconnections and interrelationships of features of input data. In general, both approaches are widely used in the pattern recognition. Since the handwriting of different writers is different, building a general recognition system that would recognize all characters with good reliability is not possible in every application. Thus recognition systems are developed to achieve reliable performances to the specific applications [1]. The problem is quite complex, and even now there is no single approach that solves it both efficiently and completely in all settings [4].

In the handwriting recognition process, an image containing text must be appropriately supplied and pre-processed. Next, the text must either undergo segmentation or feature extraction. Small processed pieces of the text will be the result, and these must undergo recognition by the system. Finally, contextual information should be applied to the recognized symbols to verify the result [4].

The advance of handwriting processing results from a combination of various elements, for example: improvements in the recognition rates, the use of complex systems to integrate various kinds of information, and new technologies such as high quality high speed scanners and cheaper and more powerful CPUs. Some handwriting recognition system allows us to input our handwriting into the system. This can be done either by controlling a mouse or using a third-party drawing tablet [5].

\section{RELATED WORKS}

Handwritten recognition is becoming more and more important in the modern world. It helps humans ease their jobs and solve more complex problems. There many studies about the Handwritten recognition. Sumedha B. Hallale, Geeta D. Salunke was designed a back propagated neural network and trained it with a set of handwritten digits. The average success rates of recognition of all digits are $91.2 \%$ [1]. a system that recognizes an English numeral, given by the user, which is already trained on the features of the numbers to be recognized using NNT (Neural network toolbox) was proposed by Amritpal kaur, Madhavi Arora [2].

Satish Lagudu, CH.V.Sarma was proposed creation of a new handwritten language recognition method. They deals with recognition of isolated handwritten characters and words using Hybrid Particle swarm Optimization and Back Propagation Algorithm [4]. MALOTHU NAGU, N VIJAY SHANKAR, K.ANNAPURNA was proposed Two techniques, are Pattern Recognition and Artificial Neural Network (ANN). Both techniques are defined and different methods for each technique is also discussed [5]. Poornima G Patil, Ravindra S Hegadi was introduced the handwritten signatures images from a standard database are preprocessed and are decomposed using wavelets. The wavelet approximation and detail coefficients in three directions are subjected to principal component analysis and are used to train the SVM classifier using a linear kernel and a nonlinear kernel which is Gaussian Radial Basis Function kernel [6].

Sameer Singh, Adnan Amin was introduced the automatic recognition of hand-printed Latin characters using artificial neural networks in combination with conventional techniques [7]. A mixture model by concurrently performing global data partition and local linear PCA. The partition is optimal or near 
optimal, which is realized by a soft competition algorithm called \&neural gas' was proposed by Bailing Zhang, Minyue $\mathrm{Fu}$, and Hong Yan [8].

Deepika Wadhwa, Karun Verma was presented an online handwritten Hindi numeral recognition system using Support Vector Machines (SVM) [9]. Ashish Gupta, Bhagwat Kakde was dealing with the unique method to identify cursive handwriting detection using artificial neural network (ANN) [10]. A method for Offline Handwritten Arabic Numerals Recognition with the use of Classifier and Feature Extraction Techniques was proposed Gita Sinha, Jitendra kumar [11]. Sabri A. Mahmoud, Sunday O. Olatunji was proposed a technique for handwritten Arabic (Indian) numerals recognition using multi-span features is presented. Angle, ring, horizontal, and vertical span features are used [12].

\section{PROPOSED SCHEME}

The proposed work uses the method of linear correlation algorithms in two dimensions for the purpose of recognizing Arabic numerals (Indian). In order to solve the problems of documents that stored in the form of image, and searching or editing it, and recognizing the Arabic digits on it. This scheme depends on the Method of automatic recognition of characters and Optical Character Recognition (OCR), they divided the process of automated reading into five phases, as shown in Figure 1.

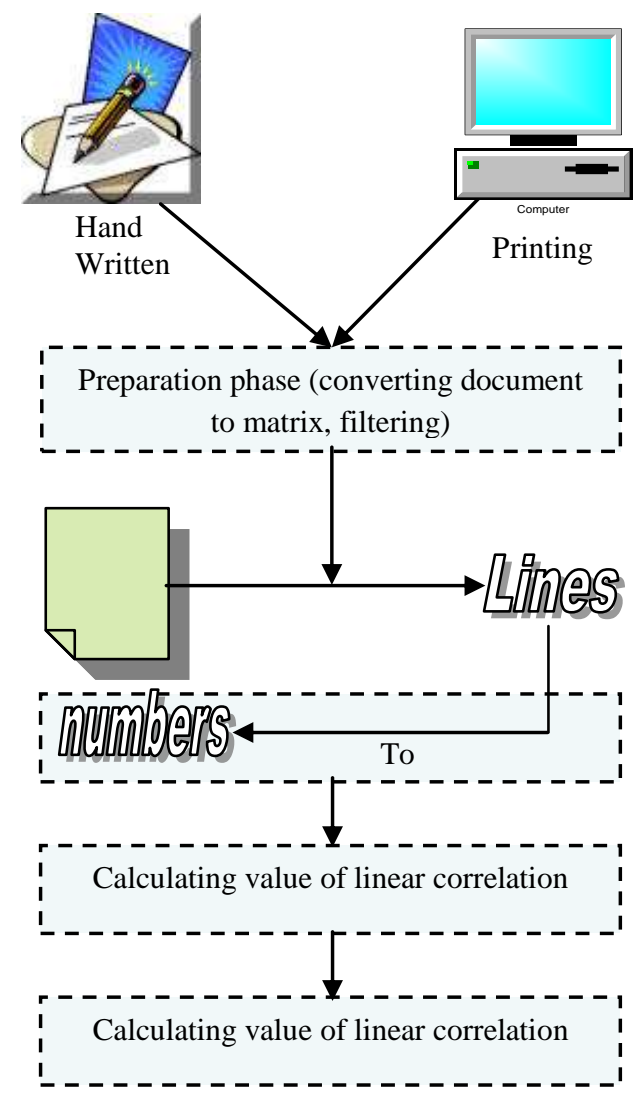

Figure. 1 Description of the system phase

The general structure of the proposed scheme is described in a diagram, representing the fifth steps of automated reading as shown in Figure 2.

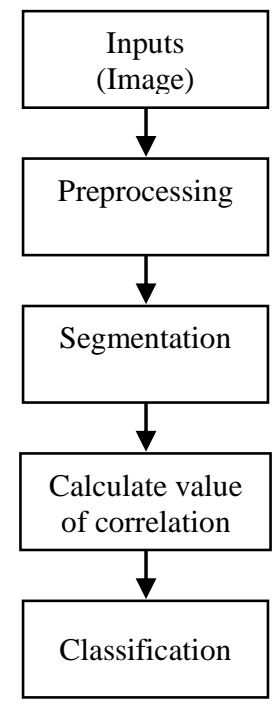

Figure. 2 General structure of the system

\section{1 inputs stage}

Is the first step in the algorithm, the system takes the original image that needed to read, from the scanner or from computer storage, this process can be represented in follow chart, as shown in Figure 3.

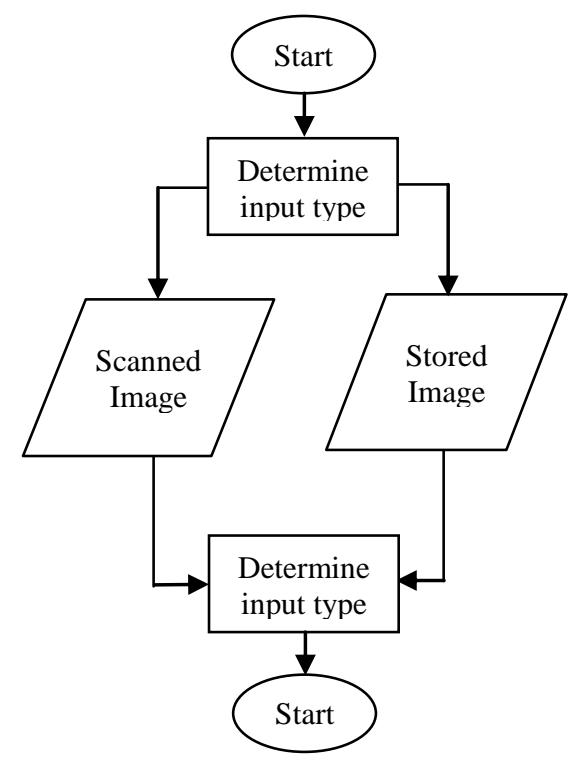

Figure 3. Input stage flow chart

\subsection{Preprocessing stage:}

Is the second step in the algorithm, the system get the original image that stored in a computer storage, then starting the preprocessing according to the following steps:

1) Checking the image, is colored or not for transforming it to gradient.

2) Converting the image to thresholding binary matrix in two dimensions, the symbol (0) representing the white squares, while the symbol (1) representing the black squares.

3) Determine the size and refine the distortions of the image and their impurities which may be associated with it. 
4) This process can be represented in follow chart, as shown in Figure 4.

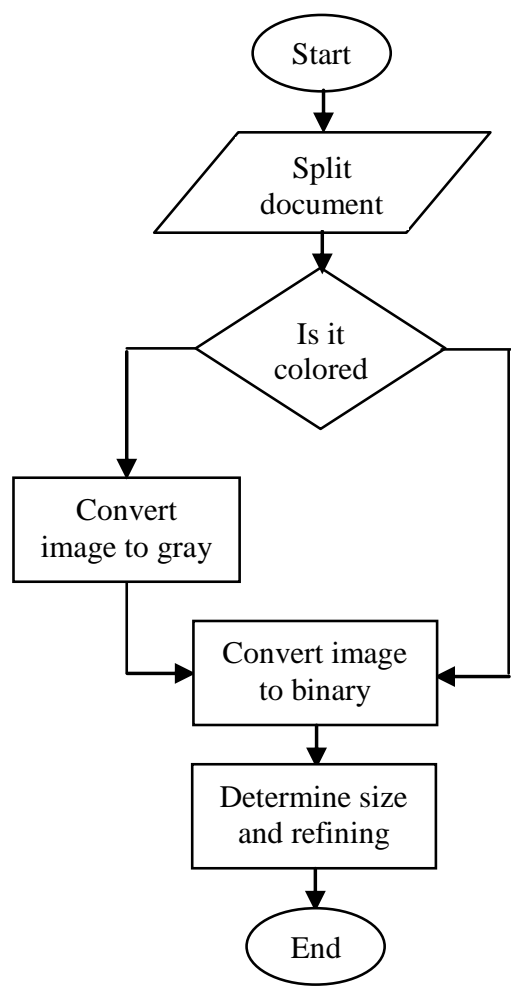

Figure 4. Preprocessing stage flow chart

\subsection{Segmentation stage:}

Is the third step in the algorithm, the inputs of the system is two dimensional matrix, as shown in Figure 5.

$$
\begin{aligned}
& \text { 9.1 }+V 7 \varepsilon \\
& r .07 \\
& \text { A to }
\end{aligned}
$$

Figure 5. Inputs of the system

The segmentation stage moves through the following steps:

1) The document divided into lines by using histogram, then calculating the number of dots in each horizontal pointed row. Then in normal state we noticed that the number of dots is equal to a zero or close to zero in some horizontal rows. Here the system detects that means this row is between two lines, (above this row and below it). Then after repeating this process on both lines, the reader may distinguished lines of the document, and divide it, as shown in Figure 6.

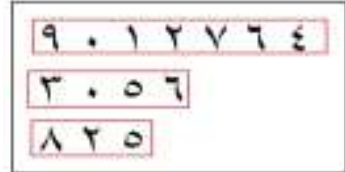

Figure 6. Dividing inputs into lines
2) Dividing the lines of the document into digits, according to the shape of the digits, based on rules and information that owned by the system, as shown in Figure 7 .

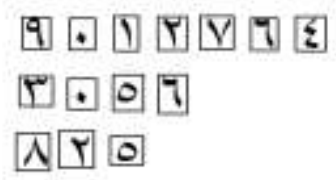

Figure 7. Dividing inputs lines into digits

3) Extracting the features by collecting the dots in each row separately, and also to the columns, then studying and analyzing the characteristics such as digit height and width, in preparation to identify the number.

4) The three steps can be represented in follow chart, as shown in Figure 8.

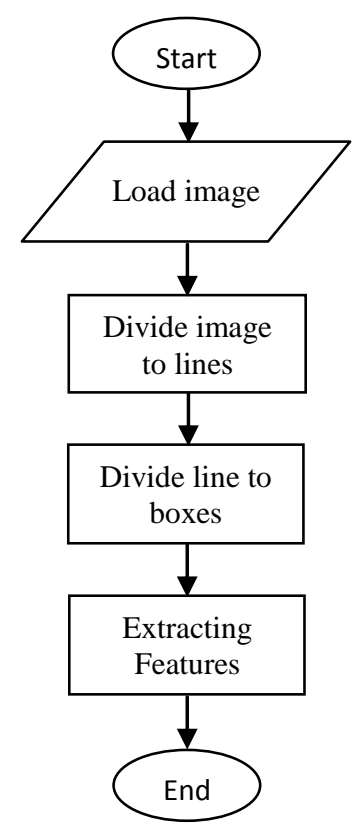

Figure 8. Segmentation stage flow chart

\subsection{Calculating correlation value stage:}

Is the fourth step in the algorithm, the system calculate correlation value of the digit matrix that want to recognize it and the template matrix by using the following equation.

$$
r=\frac{\sum_{m} \sum_{n}\left(A_{m n}-\bar{A}\right)\left(B_{m n}-\bar{B}\right)}{\sqrt{\left(\sum_{m} \sum_{n}\left(A_{m n}-\bar{A}\right)^{2}\left(B_{m n}-\bar{B}\right)^{2}\right)}}
$$

Where:

$\mathrm{r}=$ correlation value.

$A=$ initial matrix (for digit want to identify it).

$\mathrm{B}=$ template matrix (for stored digit).

$\bar{A}=$ mean of the initial matrix (for digit want to identify it).

$\bar{B}=$ mean of the template matrix (for stored digit). 
The steps of calculating the correlation value is represented in flow chart, as shown in Figure 9.

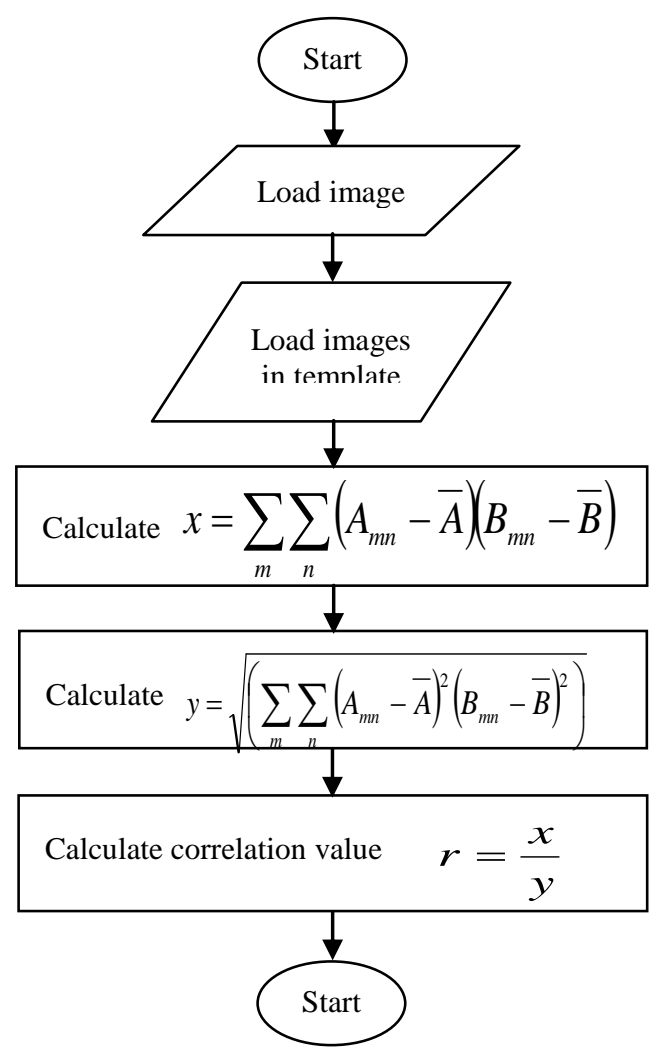

Figure 8. Calculating correlation stage flow chart

\subsection{Classification stage:}

Is the fifth step in the algorithm, the system compare the result of correlation value that calculated from the entered image with the stored message in the template, the system take the digit that is corresponding to the max value calculated to the correlation, and consider it is the digit from the entered image, then deliver the digits in text file.

\section{EVALUATING THE RESULTS:}

The system was tested on 10 images, each image contains all set of the Arabic numerals (10 digits). The result was analyzed by statistical analysis software (SPSS) to calculate the false rejection rate, which is considered a good measure to assess the Pattern Recognition Systems, as shown in Tables.

Table 1. Descriptions of the test statistics

\begin{tabular}{|l|l|l|l|l|l|l|l|l|l|l|}
\hline $\begin{array}{c}\text { number } \\
\text { Image }\end{array}$ & $\mathbf{0}$ & $\mathbf{1}$ & $\mathbf{2}$ & $\mathbf{3}$ & $\mathbf{4}$ & $\mathbf{5}$ & $\mathbf{6}$ & $\mathbf{7}$ & $\mathbf{8}$ & $\mathbf{9}$ \\
\hline One & 1 & 1 & 1 & 1 & 1 & 1 & 1 & 1 & 1 & 1 \\
\hline Two & 1 & 1 & 1 & 0 & 1 & 1 & 1 & 1 & 0 & 0 \\
\hline Three & 1 & 1 & 1 & 0 & 1 & 1 & 0 & 1 & 1 & 1 \\
\hline Four & 1 & 1 & 1 & 1 & 1 & 1 & 1 & 1 & 1 & 1 \\
\hline Five & 1 & 1 & 1 & 1 & 1 & 1 & 1 & 1 & 0 & 0 \\
\hline Six & 1 & 1 & 1 & 1 & 1 & 1 & 1 & 1 & 0 & 0 \\
\hline Seven & 1 & 1 & 1 & 1 & 1 & 1 & 0 & 1 & 1 & 1 \\
\hline Eight & 1 & 1 & 1 & 1 & 1 & 1 & 1 & 1 & 1 & 0 \\
\hline Nine & 1 & 1 & 1 & 1 & 1 & 1 & 1 & 1 & 0 & 0 \\
\hline Ten & 1 & 1 & 1 & 1 & 1 & 1 & 0 & 1 & 1 & 1 \\
\hline
\end{tabular}

Table 2. Statistics for the digit (Zero)

\begin{tabular}{|c|c|c|c|c|c|}
\hline \multicolumn{2}{|c|}{} & Frequency & Percent & $\begin{array}{c}\text { Valid } \\
\text { Percent }\end{array}$ & $\begin{array}{c}\text { cumulative } \\
\text { Percent }\end{array}$ \\
\hline Valid & $\begin{array}{l}\text { true } \\
\text { Classification }\end{array}$ & 10 & 100.0 & 100.0 & 100.0 \\
\hline
\end{tabular}

Table 3. Statistics for the digit (One)

\begin{tabular}{|c|l|c|c|c|c|}
\hline \multicolumn{2}{|l|}{} & Frequency & Percent & $\begin{array}{c}\text { Valid } \\
\text { Percent }\end{array}$ & $\begin{array}{c}\text { cumulative } \\
\text { Percent }\end{array}$ \\
\hline Valid & $\begin{array}{l}\text { true } \\
\text { Classification }\end{array}$ & 10 & 100.0 & 100.0 & 100.0 \\
\hline
\end{tabular}

Table 4. Statistics for the digit (Two)

\begin{tabular}{|c|l|c|c|c|c|}
\hline \multicolumn{2}{|l|}{} & Frequency & Percent & $\begin{array}{c}\text { Valid } \\
\text { Percent }\end{array}$ & $\begin{array}{c}\text { cumulative } \\
\text { Percent }\end{array}$ \\
\hline Valid & $\begin{array}{l}\text { true } \\
\text { Classification }\end{array}$ & 10 & 100.0 & 100.0 & 100.0 \\
\hline
\end{tabular}

Table 5. Statistics for the digit (Three)

\begin{tabular}{|c|c|c|c|c|c|}
\hline & & Frequency & Percent & $\begin{array}{c}\text { Valid } \\
\text { Percent }\end{array}$ & $\begin{array}{c}\text { cumulative } \\
\text { Percent }\end{array}$ \\
\hline \multirow[t]{3}{*}{ Valid } & $\begin{array}{l}\text { false } \\
\text { Classification }\end{array}$ & 2 & 20.0 & 20.0 & 20.0 \\
\hline & $\begin{array}{l}\text { true } \\
\text { Classification }\end{array}$ & 8 & 80.0 & 80.0 & 80.0 \\
\hline & Total & 10 & 100.0 & 100.0 & \\
\hline
\end{tabular}

Table 6. Statistics for the digit (Four)

\begin{tabular}{|c|c|c|c|c|c|}
\hline \multicolumn{2}{|l|}{} & Frequency & Percent & $\begin{array}{c}\text { Valid } \\
\text { Percent }\end{array}$ & $\begin{array}{c}\text { cumulative } \\
\text { Percent }\end{array}$ \\
\hline Valid & $\begin{array}{l}\text { true } \\
\text { Classification }\end{array}$ & 10 & 100.0 & 100.0 & 100.0 \\
\hline
\end{tabular}

Table 7. Statistics for the digit (Five)

\begin{tabular}{|c|c|c|c|c|c|}
\hline \multicolumn{2}{|l|}{} & Frequency & Percent & $\begin{array}{c}\text { Valid } \\
\text { Percent }\end{array}$ & $\begin{array}{c}\text { cumulative } \\
\text { Percent }\end{array}$ \\
\hline Valid & $\begin{array}{l}\text { true } \\
\text { Classification }\end{array}$ & 10 & 100.0 & 100.0 & 100.0 \\
\hline
\end{tabular}


Table 8. Statistics for the digit (Six)

\begin{tabular}{|c|c|c|c|c|c|}
\hline & & Frequency & Percent & $\begin{array}{c}\text { Valid } \\
\text { Percent }\end{array}$ & $\begin{array}{c}\text { cumulative } \\
\text { Percent }\end{array}$ \\
\hline \multirow[t]{3}{*}{ Valid } & $\begin{array}{l}\text { false } \\
\text { Classification }\end{array}$ & 3 & 30.0 & 30.0 & 30.0 \\
\hline & $\begin{array}{l}\text { true } \\
\text { Classification }\end{array}$ & 7 & 70.0 & 70.0 & 70.0 \\
\hline & Total & 10 & 100.0 & 100.0 & \\
\hline
\end{tabular}

Table 9. Statistics for the digit (Seven)

\begin{tabular}{|c|c|c|c|c|}
\hline & Frequency & Percent & $\begin{array}{l}\text { Valid } \\
\text { Percent }\end{array}$ & $\begin{array}{c}\text { cumulative } \\
\text { Percent }\end{array}$ \\
\hline \begin{tabular}{l|l|} 
Valid & true \\
& Classification
\end{tabular} & 10 & 100.0 & 100.0 & 100.0 \\
\hline
\end{tabular}

Table 10. Statistics for the digit (Eight)

\begin{tabular}{|c|c|c|c|c|c|}
\hline & & Frequency & Percent & $\begin{array}{c}\text { Valid } \\
\text { Percent }\end{array}$ & $\begin{array}{c}\text { cumulative } \\
\text { Percent }\end{array}$ \\
\hline \multirow[t]{3}{*}{ Valid } & $\begin{array}{l}\text { false } \\
\text { Classification }\end{array}$ & 4 & 40.0 & 40.0 & 40.0 \\
\hline & $\begin{array}{l}\text { true } \\
\text { Classification }\end{array}$ & 6 & 60.0 & 60.0 & 100.0 \\
\hline & Total & 10 & 100.0 & 100.0 & \\
\hline
\end{tabular}

Table 11. Statistics for the digit (Nine)

\begin{tabular}{|c|c|c|c|c|c|}
\hline & & Frequency & Percent & $\begin{array}{l}\text { Valid } \\
\text { Percent }\end{array}$ & $\begin{array}{c}\text { cumulative } \\
\text { Percent }\end{array}$ \\
\hline \multirow[t]{3}{*}{ Valid } & $\begin{array}{l}\text { false } \\
\text { Classification }\end{array}$ & 5 & 50.0 & 50.0 & 50.0 \\
\hline & \begin{tabular}{|l} 
true \\
Classification
\end{tabular} & 5 & 50.0 & 50.0 & 100.0 \\
\hline & Total & 10 & 100.0 & 100.0 & \\
\hline
\end{tabular}

\section{CONCULUSION}

Through the statistics analysis in the tables above, we found that the system is competence to identify amount of images that contain Arabic digits in size of $20 \times 20$ pixels, as in the following points:

1) Rate of true classification of the digits $(0,1,2,4,5$, and 7 ) is $100 \%$ and the false classification rate is $0 \%$.

2) Rate of true classification of the digit (3) is $80 \%$ and the false classification rate is $20 \%$.

3) Rate of true classification of the digit (6) is $70 \%$ and the false classification rate is $30 \%$.

4) Rate of true classification of the digit (8) is $60 \%$ and the false classification rate is $40 \%$.
5) Rate of true classification of the digits (9) is 50\% and the false classification rate is $50 \%$.

\section{REFERENCES}

[1] Sumedha B. Hallale1, Geeta D. Salunke ," OFFLINE HANDWRITTEN DIGIT RECOGNITION USING NEURAL NETWORK” International Journal of Advanced Research in Electrical, Electronics and Instrumentation Engineering(ijareeie), ISSN : 2278 8875, Vol. 2, Issue 9, September 2013, pp. 4373-4377.

[2] Amritpal kaur, Madhavi Arora, "Neural network based Numerical digits Recognization using NNT in Matlab", International Journal of Computer Science \& Engineering Survey (IJCSES), Vol.4, No.5, October 2013, pp. 19-29.

[3] S.KNERR, L.PERSONNAZ, G.DREYFUS, "Handwritten Digit Recognition by Neural Networks with Single-Layer Training", IEEE TRANSACTIONS ON NEURAL NETWORKS, vol. 3, 962(1992), pp. 118.

[4] Satish Lagudu, CH.V.Sarma, "HAND WRITING RECOGNITION USING HYBRID PARTICLE SWARM OPTIMIZATION \& BACK PROPAGATION ALGORITHM" , International Journal of Application or Innovation in Engineering \& Management (IJAIEM), ISSN: 2319 - 4847, January 2013, Volume 2, Issue 1, pp. $75-81$.

[5] MALOTHU NAGU, N VIJAY SHANKAR, K.ANNAPURNA, "A novel method for Handwritten Digit Recognition with Neural Networks", International Journal of Computer Science and Information Technologies (IJCSIT), ISSN:0975-9646, Vol. 2 (4) , 2011, pp. 1685-1692.

[6] Poornima G Patil, Ravindra S Hegadi, "Offline Handwritten Signatures Classification Using Wavelets and Support Vector Machines", International Journal of Engineering Science and Innovative Technology (IJESIT), ISSN: 2319-5967, Volume 2, Issue 4, July 2013, pp. 573-579.

[7] Sameer Singh, Adnan Amin, "Neural Network Recognition of Hand Printed Characters" Neural Computing and Applications, vol. 8, no. 1, 1999, pp. 6776.

[8] Bailing Zhang, Minyue Fu, Hong Yan, "A nonlinear neural network model of mixture of local principal component analysis: application to handwritten digits recognition", the journal of the pattern recognition society, 34 (2001), pp. 203-214.

[9] Deepika Wadhwa, Karun Verma, "Online Handwriting Recognition of Hindi Numerals using SvmDeepika", International Journal of Computer Applications (0975 888), Volume 48- No.11, June 2012, pp. 13-17.

[10] Ashish Gupta, Bhagwat Kakde, “A Novel Approach for Cursive Handwriting Detection Using Artificial Neural Network", International Journal of Advanced Research in Computer Science and Software Engineering(ijarcsse), ISSN: 2277 128X, Volume 3, Issue 11, November 2013, pp. 674-680.

[11] Gita Sinha, Jitendra kumar, "Arabic numeral Recognition Using SVM Classifier", International Journal of 
International Journal of Computer Applications Technology and Research

Volume 4- Issue 1, 01 - 06, 2015, ISSN:- 2319-8656

Emerging Research in Management \&Technology ISSN: 2278-9359 (Volume-2, Issue-5), pp. 62-67.

[12] Sabri A. Mahmoud, Sunday O. Olatunji, "HANDWRITTEN ARABIC NUMERALS RECOGNITION USING MULTI-SPAN FEATURES \& SUPPORT VECTOR MACHINES", 10th International Conference on Information Science, Signal Processing and their Applications (ISSPA 2010), 978-1-4244-71669/10/\$26.00 @2010 IEEE, pp. 618-621.

[13] Anthony, M. and Bartlett, P. ,1999, " Neural Network Learning: Theoretical Foundations". Cambridge University Press, Cambridge, UK. 1999.

[14] Bishop, C. M. ,1995, "Neural Networks for Pattern Recognition". Oxford University Press, Oxford, UK. 1995.

[15] Martin H. Luerssen, Character Recognition with Neural Networks Flinders, University of South Australia. 